\title{
Improvement of composition of CdTe thin films during heat treatment in the presence of $\mathbf{C d C l}_{2}$
}

\author{
I. M. Dharmadasa ${ }^{1}$ - O. K. Echendu ${ }^{2}$ - F. Fauzi ${ }^{1} \cdot$ N. A. Abdul-Manaf ${ }^{1}$ \\ O. I. Olusola ${ }^{1}$ H. I. Salim ${ }^{1}$ M. L. Madugu' ${ }^{1}$ A. A. Ojo ${ }^{1}$
}

Received: 18 August 2016/Accepted: 3 October 2016/Published online: 11 October 2016

(c) The Author(s) 2016. This article is published with open access at Springerlink.com

\begin{abstract}
CdCl}_{2}$ treatment is a crucial step in development of $\mathrm{CdS} / \mathrm{CdTe}$ solar cells. Although this processing step has been used over a period of three decades, full understanding is not yet achieved. This paper reports the experimental evidence for improvement of composition of CdTe layers during $\mathrm{CdCl}_{2}$ treatment. This investigation makes use of four selected analytical techniques; Photoelectro-chemical (PEC) cell, X-ray diffraction (XRD), Raman spectroscopy and Scanning electron microscopy (SEM). CdTe layers used were electroplated using three $\mathrm{Cd}$ precursors; $\mathrm{CdSO}_{4}, \mathrm{Cd}\left(\mathrm{NO}_{3}\right)_{2}$ and $\mathrm{CdCl}_{2}$. Results show the improvement of stoichiometry of $\mathrm{CdTe}$ layers during $\mathrm{CdCl}_{2}$ treatment through chemical reaction between $\mathrm{Cd}$ from $\mathrm{CdCl}_{2}$ and elemental Te that usually precipitate during CdTe growth, due to its natural behaviour. XRD and SEM results show that the low-temperature $\left(\sim 85^{\circ} \mathrm{C}\right)$ electroplated CdTe layers consist of $\sim(20-60) \mathrm{nm}$ size crystallites, but after $\mathrm{CdCl}_{2}$ treatment, the layers show drastic recrystallisation with grains becoming a few microns in size. These $\mathrm{CdCl}_{2}$ treated layers are then comparable to high temperature grown CdTe layers by the size of grains.
\end{abstract}

I. M. Dharmadasa

Dharme@shu.ac.uk

1 Materials and Engineering Research Institute, Sheffield Hallam University, Sheffield S1 1WB, UK

2 Solar Energy and Materials Science Group, Department of Physics, Federal University of Technology, PMB 1526 Owerri, Nigeria

\section{Introduction}

Cadmium telluride (CdTe) based solar cell development work is moving forward rapidly having achieved $21.5 \%$ conversion efficiency to date, for lab-scale small devices [1]. There are more than fourteen different materials growth techniques used for CdTe [2] in the literature, but to achieve devices with high efficiencies, exposure to $\mathrm{CdCl}_{2}$ and heat treatment is an essential processing step. Recent review [3] on this processing step identified several key areas requiring deep investigation in order to fully understand this crucial step, and hence further increase the conversion efficiency.

The reports in the field usually discuss about re-crystallisation, grain growth, morphology changes, passivation of grain boundaries etc. but to produce a high efficiency device, material should reach high electronic quality in every aspect. Therefore, the changes in electrical conductivity, doping concentration, removal of defects, and improvements in material composition etc. should be thoroughly investigated in order to achieve deep understanding of this process. As an effort towards this aim, we have carried out ultra-violet photo-electron emission spectroscopy (UPS) work [4] in order to determine the position of Fermi level of the top CdTe surface, and hence gain indirect information about the material's electrical conductivity and doping concentration. We have also carried out comprehensive photoluminescence (PL) work [5] on CdTe layers in order to examine the defects present and help in minimisation and removal during processing steps. In a previous publication by Basol [6], there is a suggestion of elimination of any excess $\mathrm{Te}$ through reaction with $\mathrm{CdCl}_{2}$ as a possible mechanism. A more recent report by Ricárdez-Jiménez et al. [7] also present some experimental results indicating the improvement of stoichiometry of 
CdTe layer during $\mathrm{CdCl}_{2}$ treatment. The experimental evidence presented in this paper concentrates on the composition improvements of CdTe layers, using X-ray diffraction (XRD) and Raman spectroscopy, on three different CdTe material layers electroplated from $\mathrm{CdSO}_{4}$, $\mathrm{Cd}\left(\mathrm{NO}_{3}\right)_{2}$ and $\mathrm{CdCl}_{2}$ precursors. SEM results are also included in order to examine the recrystallisation and grain growth during this processing step.

\section{Experimental details}

\subsection{Experimental techniques used}

In order to grow required materials for this investigation, previous knowledge on electroplating of CdTe was used. Therefore, the photoelectrochemical (PEC) cell work is summarised here in order to grow required materials for this work. XRD, Raman and SEM techniques have been selected for characterisation of the CdTe layers.

\subsubsection{Photo-electrochemical cell studies}

Photoelectrochemical cell work was used to determine the electrical conductivity of CdTe layers grown on glass/transparent conducting oxide layer (FTO-Fluorine doped tin oxide). Conventional Hall effect measurements cannot be carried out due to the conducting layer underneath. The glass/FTO/CdTe substrates were immersed in a suitable electrolyte such as $\mathrm{Na}_{2} \mathrm{~S}_{2} \mathrm{O}_{3}$ solution and the open circuit voltage of the CdTe/electrolyte junction was measured as the PEC signal with respect to a carbon electrode immersed in the same electrolyte. The system was calibrated with a known semiconductor like CdS and then the sign of PEC signal was used to determine the electrical conductivity type. In this system, positive PEC signal represents a p-type semiconducting layer.

\subsubsection{X-ray diffraction studies}

X-ray diffraction (XRD) studies were carried out using Philips X'pert pro-diffractometer with a $\mathrm{Cu}-\mathrm{K} \alpha$ excitation wavelength of $1.541 \AA$. Diffraction patterns were recorded in the $2 \theta$ range of $20^{\circ}$ to $70^{\circ}$ for each layer. These patterns were used to identify the crystal structures, crystal phases present and lattice planes for the observed diffraction peaks from atomic planes of deposited thin films. In this work, XRD analysis were limited only to recognition of phases present in these layers. Other detailed analyses have been reported in previous publications [8-11].

\subsubsection{Raman studies}

Raman studies were carried out with a Renishaw Raman microscope with a CCD detector and $514 \mathrm{~nm}$ argon ion laser source. It is used to identify the various vibrational modes of the molecules in the material by shining the laser beam of light onto the CdTe thin films. Raman spectroscopy is an alternative method to identify material phases and determine the degree of crystallinity of the thin films and Raman spectra are generally applied as fingerprints for identifying material phases. This fast technique is also suitable for quality control of materials grown in a production line. Again, the analyses were limited only to identifying the phases present in these material layers.

\subsubsection{Scanning electron microscopy studies}

SEM studies were carried out using FEI Nova NanoSEM 200. This system offers high resolutions of up to $1 \mathrm{~nm}$ in high vacuum mode with an accelerating voltage of up to $30 \mathrm{kV}$. SEM is a type of electron microscopy that produces images of a sample by scanning it with a focused beam of electrons with the magnifications of up to $1,000,000$ and ultimate resolution of $1 \mathrm{~nm}$. It can provide information on surface topography, grain structure and grain size of the sample. In this work, SEM measurement was used to study the microstructure and grain size of CdTe thin films.

\subsection{Details of materials used}

For all research carried out in this work, electroplated CdTe layers were used. The latest information on electrodeposition of CdTe and their properties are presented in our recent publications [8-11]. CdTe material easily exists in both $\mathrm{n}$ - and p- type electrical conduction [12], and this has also been reported for electrodeposited CdTe in the literature [13, 14]. The comprehensive research programme at Sheffield Hallam University has shown that CdTe can be easily grown with p-type and n-type electrical conductivity [8-10]. As the composition changes from Te-richness to Cd-richness at parts per million (ppm) level, electrical conduction type changes from p-type to n-type.

Figure 1 shows typical change of electrical conduction type as a function of growth voltage for CdTe deposited from $\mathrm{CdSO}_{4}$ precursor. The electrical conductivity type changes from p-type to n-type by varying the composition, depending on the electrodeposition voltage. In between, there exists an inversion growth voltage $\left(\mathrm{V}_{\mathrm{i}}\right)$, where the material shows $\mathrm{Cd}: \mathrm{Te}=50: 50$ stoichiometry in un-doped electrolyte situation. Out of the two semiconductor elements ( $\mathrm{Cd}$ and $\mathrm{Te}), \mathrm{Te}$ deposits easily at lower cathodic voltages than $\mathrm{Cd}$ due to the difference in redox potential values $\left(\mathrm{E}^{\circ}=+0.530 \mathrm{~V}\right.$ for $\mathrm{Te}$ and $\mathrm{E}^{\circ}=-0.403 \mathrm{~V}$ for 


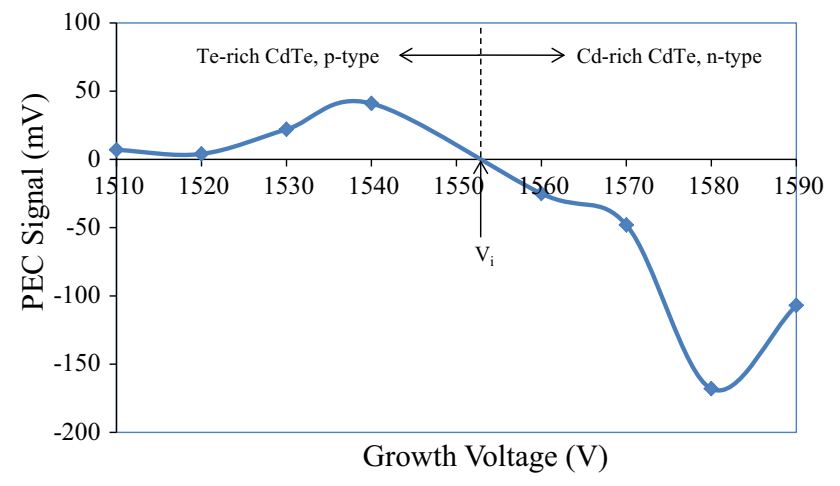

Fig. 1 Typical photoelectrochemical (PEC) cell results showing the variation of electrical conduction type of electroplated CdTe from $\mathrm{CdSO}_{4}$ precursor. Positive and negative PEC signals indicate p-type and n-type materials respectively while zero PEC value indicates i-type material grown at growth voltage of $\mathrm{V}_{\mathrm{i}}$

Cd) [15]. Therefore, the layers grown below $V_{i}$ are rich in $\mathrm{Te}$ and p-type, and those grown above $\mathrm{V}_{\mathrm{i}}$ are rich in $\mathrm{Cd}$ and n-type in electrical conduction. Although this control exits for as-grown CdTe layers, heat treatment in the presence of $\mathrm{CdCl}_{2}$ introduces an un-known step in device processing. Therefore, in order to investigate composition changes, purposely prepared Te-rich, CdTe layers from three different $\mathrm{Cd}$ precursors were used in this work. The details of the material layers used are summarised in Table 1.

Electrical conductivity change of $\mathrm{CdTe}$ is clearly observed experimentally for electroplated CdTe. In a similar way, these changes could occur during any material growth technique by slight variation of stoichiometry. $\mathrm{Cd}$ :Te ratio can easily change during growth, depending on conditions such as source and substrate temperatures.

Te-rich CdTe layers under three different processing conditions were used in this investigation; as-grown CdTe layers, heat treated CdTe layers in atmospheric conditions and $\mathrm{CdCl}_{2}$ treated $\mathrm{CdTe}$ layers. CdTe layers were grown in the vicinity of the inversion growth voltage $\left(\mathrm{V}_{\mathrm{i}}\right)$ to keep the crystallinity of the material high. However, to examine how the stoichiometry changes after the heat treatment in air and $\mathrm{CdCl}_{2}$ treatment, material layers were grown on Terich side in order to purposely change the composition. Heat treatment in air was carried out at $\sim 400{ }^{\circ} \mathrm{C}$ for 15 min in atmospheric condition. For $\mathrm{CdCl}_{2}$ treatment, the as-deposited layers were dipped in a $10 \%$ aqueous $\mathrm{CdCl}_{2}$ solution, dried in air and heat treated at $\sim 400{ }^{\circ} \mathrm{C}$ for $15 \mathrm{~min}$ in air. In all cases, oxygen is present due to growth in aqueous media and heating in atmospheric condition. These three types of layers grown using three different precursors were examined using XRD and Raman for detecting composition changes under above processing conditions. SEM studies were carried out in order to examine grain sizes and morphology changes during these processing steps. Conclusions made in this work are mainly based on qualitative rather than quantitative analysis.

\section{Experimental results}

\subsection{XRD results for $\mathrm{CdTe}$ grown from $\mathrm{CdSO}_{4}$ precursor}

X-ray diffraction patterns obtained under identical conditions for as-deposited, heat-treated in air and $\mathrm{CdCl}_{2}$-treated, Te-rich CdTe layers grown from $\mathrm{CdSO}_{4}$ precursor are shown in Fig. 2. For comparison and ease of analysis, an XRD pattern of the substrate, glass/FTO has also been included.

As-deposited layers with the Te-richness show the presence of cubic CdTe phase, observed by reflections from (111), (220) and (311) crystal planes. Additional XRD peaks corresponding to elemental hexagonal Te, are shown by the peaks (101), (102) and (110) as indicated in Fig. 2a showing the existence of the second phase. As expected, the layers grown on the Te-rich side are nonstoichiometric and consist of the two main phases cubic $\mathrm{CdTe}$ and hexagonal elemental Te. The existence of Te is in the crystalline form, and may be present as small precipitates embedded in the layer or as a surface layer on the deposited material. XRD cannot distinguish the difference between these two, and cannot detect amorphous $\mathrm{Te}$ phases.

Heat treatment in air increases the sharpness of both CdTe and Te peaks as shown in Fig. 2b. This is mainly due to re-crystallisation of both phases due to effect of heat energy. Te peaks are enhanced more dramatically showing

Table 1 Summary of growth conditions applied for electroplated CdTe layers used in this investigation

\begin{tabular}{|c|c|c|}
\hline Material used & Growth details & Reference \\
\hline CdTe grown from $\mathrm{CdSO}_{4}$ pre-cursor & $\begin{array}{l}1.0 \mathrm{M} \mathrm{CdSO}_{4}, \text { Low level of } \mathrm{TeO}_{2}, \mathrm{pH}=2.00, \\
\text { Temp. }=85^{\circ} \mathrm{C} \text {, 2-electrode system, Te-rich CdTe }\end{array}$ & [9] \\
\hline CdTe grown from $\mathrm{Cd}\left(\mathrm{NO}_{3}\right)_{2}$ precursor & $\begin{array}{l}1.0 \mathrm{M} \mathrm{Cd}\left(\mathrm{NO}_{3}\right)_{2}, \text { Low level of } \mathrm{TeO}_{2}, \mathrm{pH}=2.00, \\
\text { Temp. }=85^{\circ} \mathrm{C} \text {, 2-electrode system, Te-rich CdTe }\end{array}$ & {$[10]$} \\
\hline CdTe grown from $\mathrm{CdCl}_{2}$ pre-cursor & $\begin{array}{l}\text { 1.0 } \mathrm{M} \mathrm{CdCl}_{2} \text {, Low level of } \mathrm{TeO}_{2}, \mathrm{pH}=2.00, \\
\text { Temp. }=65^{\circ} \mathrm{C}, 3 \text {-electrode system, Te-rich CdTe }\end{array}$ & {$[11]$} \\
\hline
\end{tabular}


Fig. 2 XRD patterns of (a) asdeposited, $(b)$ annealed in air and (c) $\mathrm{CdCl}_{2}$-treated, Te-rich CdTe layers grown from $\mathrm{CdSO}_{4}$ precursor. The XRD pattern obtained for glass/FTO is also included to identify peaks arising from FTO layer

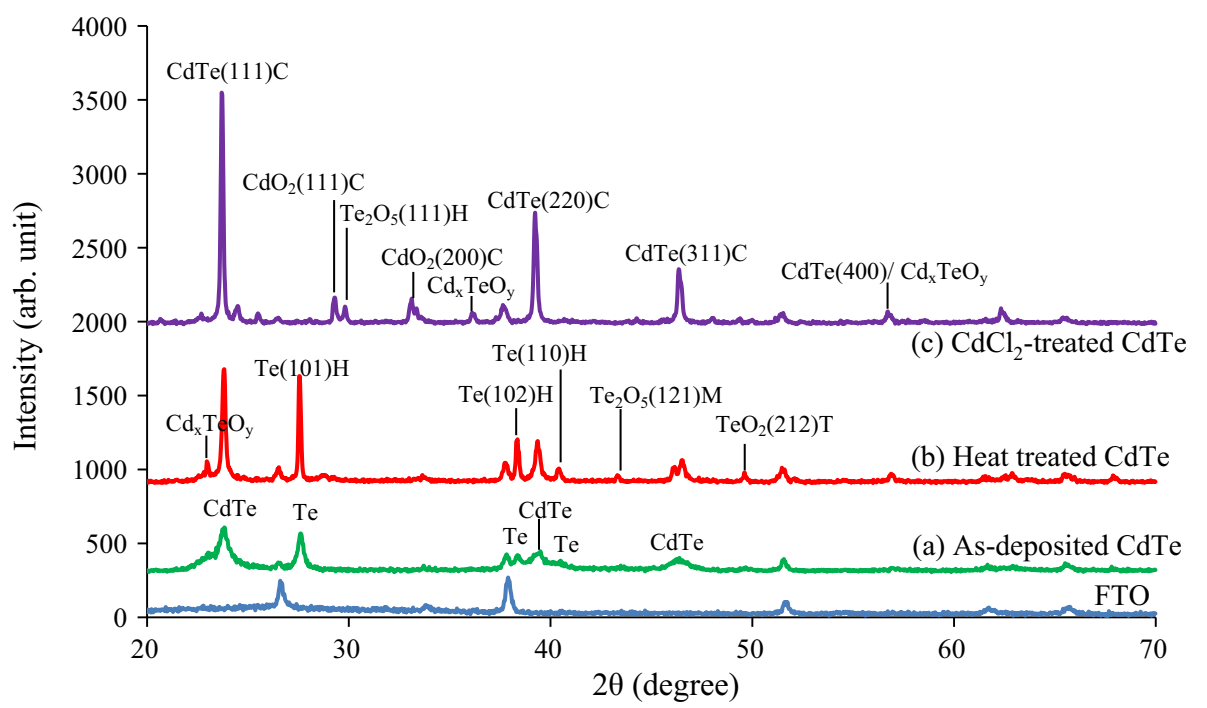

re-crystallisation of poly-crystalline and any amorphous $\mathrm{Te}$ present in the material layer. $\mathrm{Cd}_{\mathrm{x}} \mathrm{TeO}_{\mathrm{y}}$ peak and Te-oxide peaks show the oxidation of the surface layer and incorporation of oxygen in the material on the surface, as expected under these processing conditions.

After heat treatment in the presence of $\mathrm{CdCl}_{2}$ on the surface, all the elemental Te related XRD peaks have disappeared (see Fig. 2c). The three dominant peaks observed are mainly due to improved poly-crystalline $\mathrm{CdTe}$. This shows that $\mathrm{CdCl}_{2}$ treatment removes excess $\mathrm{Te}$ phase from the layer and makes the CdTe layer more stoichiometric and better crystalline. This could happen due to two mechanisms. The most plausible one is the reaction between $\mathrm{Cd}$ from $\mathrm{CdCl}_{2}$ and elemental $\mathrm{Te}$ in the layer to form CdTe. The second mechanism could be the sublimation of excess $\mathrm{Te}$ and oxidised $\mathrm{Te}$ compounds during heat treatment. XRD peaks arising from $\mathrm{CdO}_{2}, \mathrm{Te}_{2} \mathrm{O}_{5}$ and $\mathrm{Cd}_{\mathrm{x}} \mathrm{TeO}_{\mathrm{y}}$ show the residue of native oxides and other compounds left on the surface after this treatment. These peaks are expected when $\mathrm{CdTe}$ layers with $\mathrm{CdCl}_{2}$ are heat treated in atmospheric conditions in the presence of oxygen. The results above therefore confirm the improvement of stoichiometry and reaching Cd-richness in CdTe layer during $\mathrm{CdCl}_{2}$ treatment.

\subsection{XRD results for $\mathrm{CdTe}$ grown from $\mathrm{Cd}\left(\mathrm{NO}_{3}\right)_{2}$ precursor}

Similar experimental results obtained for Te-rich CdTe layers grown using $\mathrm{Cd}\left(\mathrm{NO}_{3}\right)_{2}$ precursor are shown in Fig. 3. It is clear that excess $\mathrm{Te}$ is present in the as-deposited CdTe layer due to growth on Te-rich side of $\mathrm{V}_{\mathrm{i}}$. Heat treatment in air improves Te peak intensities indicating crystallisation of $\mathrm{Te}$ and $\mathrm{CdCl}_{2}$ treatment drastically reduces this phase. The presence of $\mathrm{Cd}_{\mathrm{x}} \mathrm{TeO}_{\mathrm{y}}$ layer on the heat treated surface is clear due to natural oxidation during heating in air.

\subsection{XRD results for CdTe grown from $\mathrm{CdCl}_{2}$ precursor}

Figure 4 shows similar experimental results obtained for Te-rich CdTe layers electroplated from $\mathrm{CdCl}_{2}$ precursor. As observed in the above two cases, Te and CdTe crystallisation takes place during heat treatment in air forming $\mathrm{Cd}_{\mathrm{x}} \mathrm{TeO}_{\mathrm{y}}$ and Te-oxides in the film. $\mathrm{CdCl}_{2}$ treatment, clearly removes excess $\mathrm{Te}$ and $\mathrm{Te}$-compounds from the layer through the chemical reaction with $\mathrm{Cd}$ from $\mathrm{CdCl}_{2}$ and sublimation during heat treatment. Crystallinity of CdTe has dramatically improved after $\mathrm{CdCl}_{2}$ treatment.

From these experiments, it is clear that the improvement of stoichiometry of CdTe layer due to $\mathrm{CdCl}_{2}$ treatment takes place during this crucial processing step. In this work, purposely grown Te-rich CdTe layers were used to observe chemical and phase changes. However, during device optimisation process, Te-richness even at ppm level affects the doping concentration and hence the device performance [Fig. 19 in Reference 8]. Those changes at ppm level cannot be observed using analytical techniques such as $\mathrm{XRD}$ and Raman spectroscopy. This is the main reason to use purposely grown Te-rich CdTe layers for this investigation. Our previous work on UPS [4] however enables us to detect the position of Fermi level in the bandgap, and hence obtain indirect information on changes in doping concentrations. The photoluminescence work presented in ref. 5, clearly shows the removal of defects during $\mathrm{CdCl}_{2}$ treatment. 
Fig. 3 XRD patterns of $(a)$ asdeposited, $(b)$ annealed in air and (c) $\mathrm{CdCl}_{2}$ treated, Te-rich CdTe layers grown using $\mathrm{Cd}\left(\mathrm{NO}_{3}\right)_{2}$ precursor. The patterns obtained for glass/FTO are also included to identify peaks arising from FTO layer

Fig. 4 XRD patterns of $(a)$ asdeposited, $(b)$ annealed in air and $(c) \mathrm{CdCl}_{2}$ treated, Te-rich $\mathrm{CdTe}$ layers grown using $\mathrm{CdCl}_{2}$ precursor. The patterns obtained for glass/FTO are also included to identify peaks arising from FTO layer
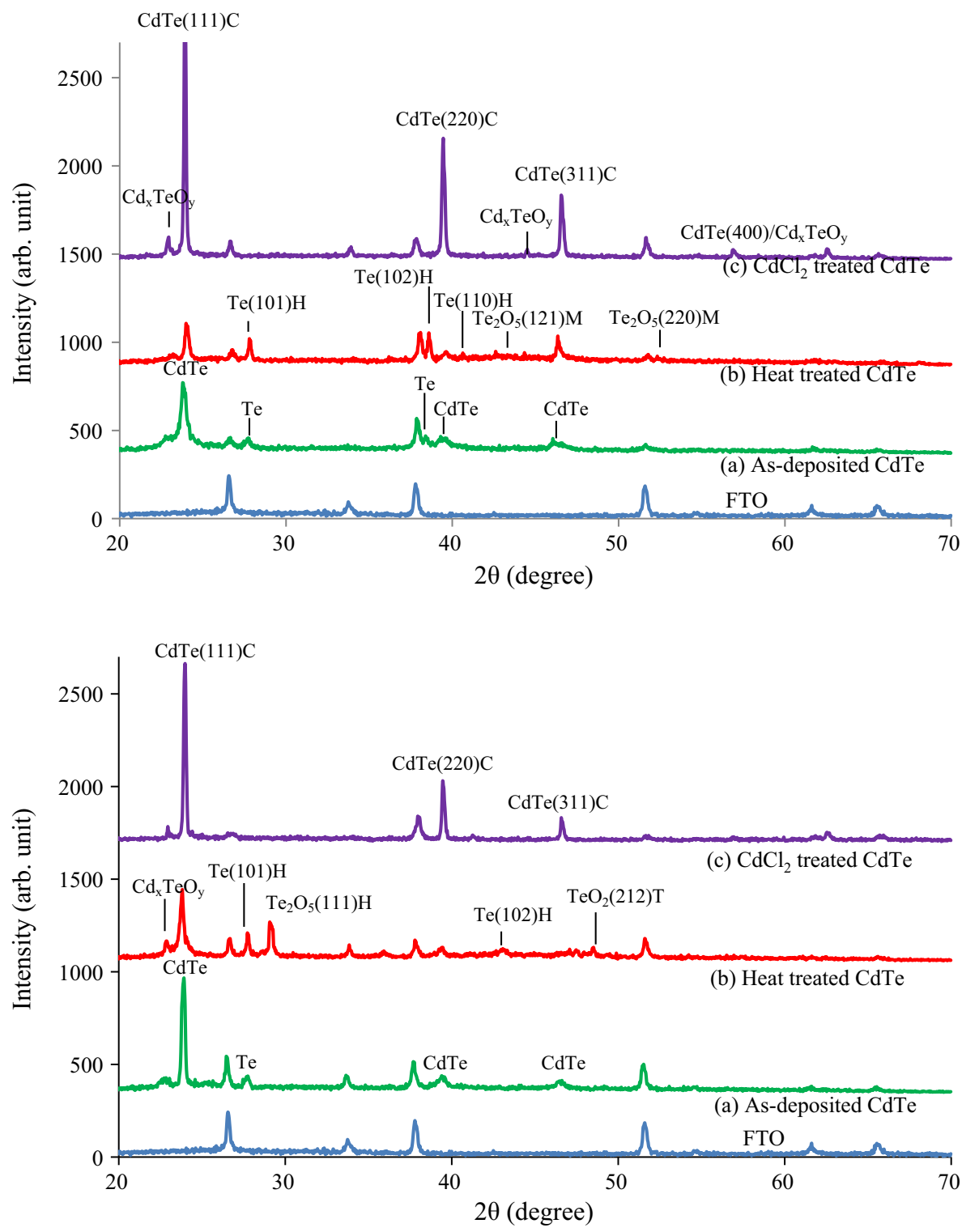

\section{Raman spectroscopy results}

\subsection{Raman results for $\mathrm{CdTe}$ grown from $\mathrm{CdSO}_{4}$ precursor}

Raman results for as-deposited, heat treated in air and $\mathrm{CdCl}_{2}$ treated CdTe layers grown using $\mathrm{CdSO}_{4}$ precursor are shown in Fig. 5. The two peaks at 165 and $329 \mathrm{~cm}^{-1}$ correspond to CdTe vibrations. The peaks at 121 and $260 \mathrm{~cm}^{-1}$ arise due to vibrations from elemental Te, indicating the existence of two phases, CdTe and elemental $\mathrm{Te}$ in the electrodeposited layers under investigation. The Raman peak observed at $\sim 140 \mathrm{~cm}^{-1}$ is a combination of $\mathrm{TO}(\mathrm{CdTe})$ and elemental Te [E(Te)]. Therefore, this peak cannot be taken as a guide to observe any stoichiometric changes in the layers. The following discussion therefore, avoids this particular peak due to this overlap.
Heat treatment in air clearly enhances the $\mathrm{LO}(\mathrm{CdTe})$ vibrations indicating crystallisation of $\mathrm{CdTe}$ and shows the existence of $\mathrm{Te}$ phase. After the layer has been $\mathrm{CdCl}_{2}$ treated, peak corresponding to $121 \mathrm{~cm}^{-1}$ has been completely removed and CdTe related vibrations have drastically improved. This confirms the results observed from $\mathrm{XRD}$; the reduction of elemental Te from the layer after $\mathrm{CdCl}_{2}$ treatment, and improvement of the crystallinity of CdTe.

\subsection{Raman results for CdTe grown from $\mathrm{Cd}\left(\mathrm{NO}_{3}\right)_{2}$ precursor}

Figure 6 shows similar results obtained for Te-rich CdTe layers grown from $\mathrm{Cd}\left(\mathrm{NO}_{3}\right)_{2}$ precursor. The presence of $\mathrm{Te}$ in as-deposited CdTe layers and the removal of Te after $\mathrm{CdCl}_{2}$ treatment are clear from these results. 
Fig. 5 Raman spectra of CdTe layers electroplated from $\mathrm{CdSO}_{4}$ precursor for asdeposited, heat treated in air and $\mathrm{CdCl}_{2}$ treated layers. Note the reduction of Te peak at $121 \mathrm{~cm}^{-1}$ after $\mathrm{CdCl}_{2}$ treatment, and the enhancement of CdTe related peaks

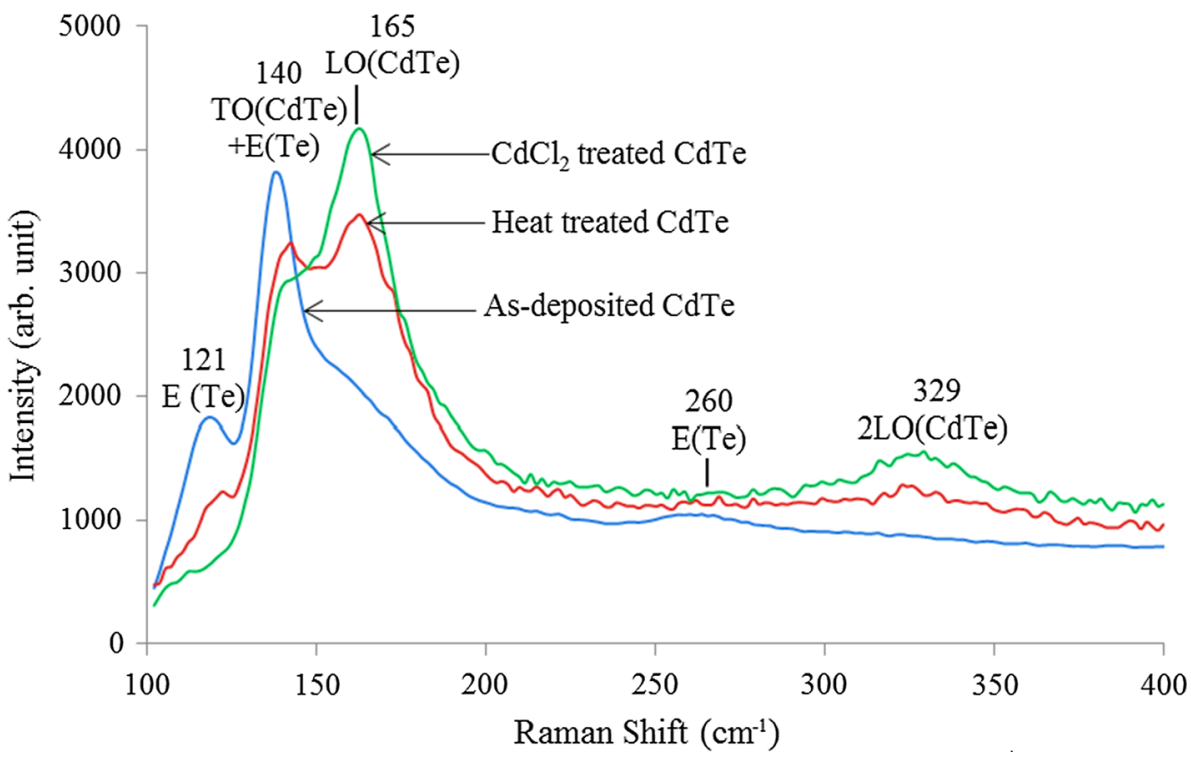

Fig. 6 Raman spectra of CdTe layers grown from $\mathrm{Cd}\left(\mathrm{NO}_{3}\right)_{2}$ precursor for as-deposited, heat treated and $\mathrm{CdCl}_{2}$ treated layers. Note the reduction of Te peak at $121 \mathrm{~cm}^{-1}$ and enhancement of CdTe related peak at $165 \mathrm{~cm}^{-1}$ after $\mathrm{CdCl}_{2}$ treatment

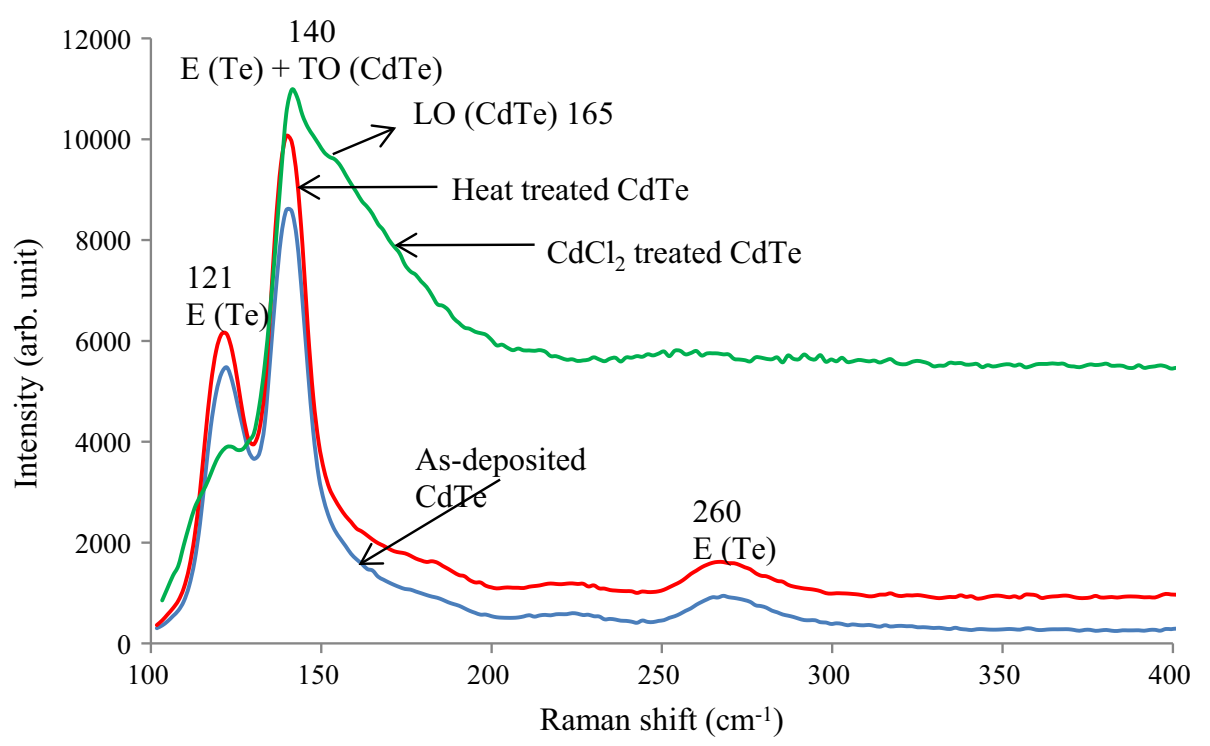

\subsection{Raman results for $\mathrm{CdTe}$ grown from $\mathrm{CdCl}_{2}$ precursor}

Figure 7 presents the Raman results obtained for Te-rich CdTe layers grown using $\mathrm{CdCl}_{2}$ precursor. The existence of elemental $\mathrm{Te}$ in the as-deposited $\mathrm{CdTe}$ and removal of $\mathrm{Te}$ during $\mathrm{CdCl}_{2}$ treatment is very clear. Because of the rapid data acquisition in Raman spectroscopy, these spectra can be used as finger prints to identify the nature of CdTe layers grown in a manufacturing line. This can therefore be used as a quality control method in a large scale production line.

Large number of experimental results from the literature and overall results from our group shows that the devices made out of as-deposited layers are comparatively poor, producing $\sim 0-4 \%$ efficient devices. These materials are rich in Te, p-type in electrical conduction and full of defects [5], and contain small grains with poor crystallinity. However, when the layers are $\mathrm{CdCl}_{2}$ treated before device fabrication, efficiency increases into mid-teens. This is due to the combination of many reasons; recrystallization and formation of larger grains, defect removal and becoming closer to stoichiometry. From our experimental work (not presented in this paper), we observe that excess Te inclusion in ppm levels in the layers are detrimental and should be avoided in device quality materials. Cd-richness in the material always produces better performing devices. The experimental evidence presented in this work demonstrated the removal of excess Te from the layer causing drastic change in composition and hence the doping concentration in the material. 
Fig. 7 Raman spectra of CdTe layers grown from $\mathrm{CdCl}_{2}$ precursor for as-deposited, heat treated in air and $\mathrm{CdCl}_{2}$ treated layers. Note the reduction of $\mathrm{Te}$ peak at $121 \mathrm{~cm}^{-1}$

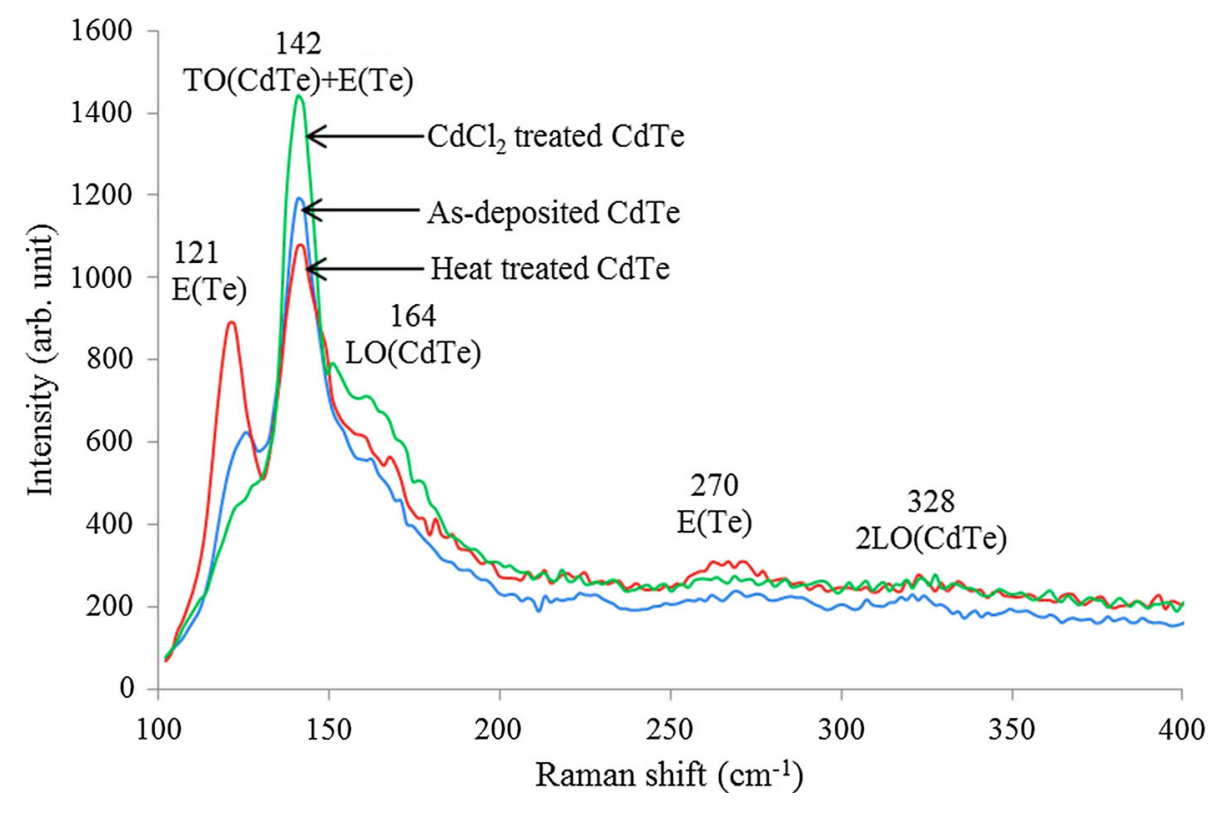

\section{Scanning electron microscopy studies}

Scanning electron microscopy studies were carried out on all three types of CdTe layers after three processing conditions, in order to explore grain growth and changes in surface morphology. Figure 8 summarises the complete results set for material surfaces studied in this project.

It is clear from the SEM images that as-deposited layers grown at $\sim 85^{\circ} \mathrm{C}$ consists of small crystallites (grains) in the range of $\sim(20-60) \mathrm{nm}$. The grain size depends on the growth conditions and precursor used, and largest grains are produced when grown using $\mathrm{CdCl}_{2}$ precursor. It is also worth noting the morphology difference in these layers. In the case of sulphate and nitrate precursors, the crystallites form large agglomerations (clusters), but in the case of chloride precursor, crystallites remain as individual grains.

Heat treatment in atmospheric condition enhances the grain growth. However, exposure to high temperatures for a long period of time causes formation of larger grains but loss of materials are observed [10, 11]. This causes columnar growth and open up gaps or pinholes at grain boundaries, creating detrimental effects for devices.

$\mathrm{CdCl}_{2}$ treatment with optimised temperature and heat treatment duration shows drastic grain growths producing grain sizes up to $\sim 5$ microns. These material layers show well connected grains and comparable to CdTe grown by high temperature techniques such as closed space sublimation method. Over heat treatment due to high temperature or lengthy durations causes loss of material and columnar growth, thereby resulting to opening up of pinholes at grain boundaries. These pinholes are detrimental in device performance due to electrically shorting of devices.
This effect is more dramatic when the CdTe layers are thin in the range of 1.0-2.0 microns.

\section{Discussion}

The work presented in this paper shows that $\mathrm{CdCl}_{2}$ treatment carried out on CdTe layers tend to remove any excess Te from the layer and make the CdTe material more stoichiometric. This certainly helps in increasing the crystallinity of CdTe since there is only one phase in the layer. Presence of $\mathrm{CdCl}_{2}$ on the surface also prevents material losses through sublimation. This treatment clearly converts Te-rich CdTe layers into stoichiometric CdTe, more suitable for device fabrication.

This observation is consistent with our overall observations in CdTe solar cell devices [8-11]. When the asgrown material is rich in Te and p-type in electrical conduction, the devices produced are weak in performance [16]. However, when the material reaches stoichiometry and just enters the Cd-richness in ppm level, the solar cell device performance improves and the efficiency reaches their highest values. The work by Jaegermann's group [17] reporting better devices on CSS grown CdTe, when Fermi level just moves into the upper half of the bandgap (n-type region) is a good example. When material enters into deep Cd-richness, the crystallinity suffers again due to presence of two phases and device performance goes down. Current understanding is that the material should be very close to stoichiometry, on Cd-rich side and n-type in electrical conductivity in order to achieve high performing devices.

It is interesting to re-visit the photoluminescence work and Schottky barrier contact work carried out on single 
(i)

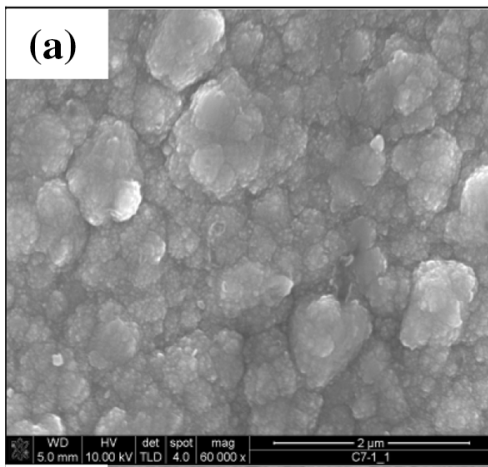

(b)

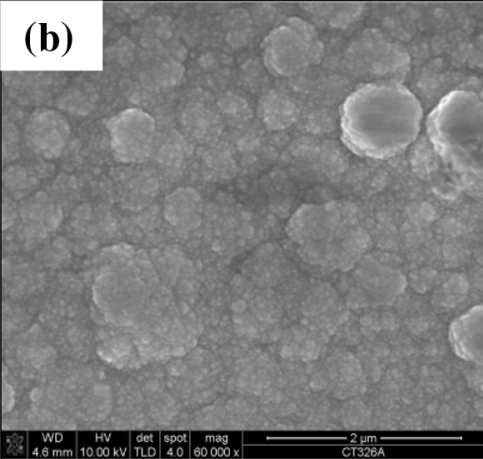

(c)



(ii)

(iii)


Fig. 8 SEM images of electroplated CdTe layers from $\mathbf{a ~} \mathrm{CdSO}_{4}, \mathbf{b} \mathrm{Cd}\left(\mathrm{NO}_{3}\right)_{2}$ and $\mathbf{c} \mathrm{CdCl}_{2}$ precursors, under (i) as-deposited, (ii) air annealed and (iii) $\mathrm{CdCl}_{2}$ treated processing conditions

crystal CdTe wafers $[18,19]$. When the wafer is etched so that the surface is rich in Te, the defect levels in the midgap and the upper half of the bandgap are more dominant. The metal contacts fabricated on these surfaces show low Schottky barriers [19-21]. On the other hand, when the surfaces are etched to produce Cd-rich layers, defect levels in the upper half of the bandgap and in the mid-gap disappear, and defects in the lower half of the band gap closer to the valence band become dominant. The metal contacts on these surfaces make excellent Schottky diodes with high potential barriers close to $\sim 1.20 \mathrm{eV}$. It appears that all these results become consistent with the results reported recently on PL studies on thin film CdTe [4].

In the $\gamma$ - and X-ray detectors research work based on insulating and semi-insulating $\mathrm{CdTe}$, it is well known that Te precipitation is common in CdTe material, irrespective of the growth technique [22-26]. It is also known that treatment similar to $\mathrm{CdCl}_{2}$, removes these precipitated Te [27]. Therefore, in PV development with CdTe thin films, Te precipitation occurs during growth of CdTe due to natural behaviour of Te even at ppm level, un-detected by many analytical techniques. Therefore, the electronic quality of Te-rich CdTe layers suffers drastically. $\mathrm{CdCl}_{2}$ treatment removes this excess $\mathrm{Te}$, improves stoichiometry of the material, converts CdTe layer into Cd-richness in ppm level and the electronic properties improve drastically. This gives rise to high efficiency of CdS/CdTe solar cells after $\mathrm{CdCl}_{2}$ treatment.

SEM studies show that CdTe layers electroplated at low temperatures $\left(\sim 85^{\circ} \mathrm{C}\right)$ have smaller grains in the range $\sim(20-60) \mathrm{nm}$. However, the $\mathrm{CdCl}_{2}$ treatment produces drastic grain growths forming columns across the thin 
films, showing a few microns size in diameter. These grain sizes are comparable to the CdTe grains produced by high temperature growth techniques like closed space sublimation.

\section{Conclusions}

The results reported in this paper using three different kinds of CdTe layers deposited from sulphate, nitrate and chloride precursors are consistent and reproducible. Results show that heat treatment of CdTe thin films in the presence of $\mathrm{CdCl}_{2}$ tends to remove any elemental Te in the deposited layer making the $\mathrm{CdTe}$ layer more stoichiometric. In addition, the morphology of the material layers grown at low temperatures of $\sim 85^{\circ} \mathrm{C}$, change drastically after $\mathrm{CdCl}_{2}$ treatment. Small grains of the size $\sim(20-60) \mathrm{nm}$ increase up to few microns size, comparable with other CdTe layers grown by high temperature growth methods such as closed space sublimation technique. As a result of this treatment, CdTe layer becomes stoichiometric, more crystalline, close to Cd-richness and therefore help in producing high efficiency solar cell devices. This work highlights that the detrimental effect of Te-richness in CdTe layers and requirements of stoichiometric and slightly Cd-rich CdTe layers for development of high efficiency solar cells.

Acknowledgments Authors would like to thank Jane Wellings, Gaafar Muftah, Dahiru Diso, Ajith Weerasinghe, Fijay Fauzi, Thad Druffel, Ruvini Dharmadasa, Brandon Lavery, Jacek Jasinsky, Andrey Sherehiy, Tatiana Krentsel and Gamini Sumanasekera for their contributions to this research programme in different ways, in the past to reach current conclusions.

Open Access This article is distributed under the terms of the Creative Commons Attribution 4.0 International License (http://crea tivecommons.org/licenses/by/4.0/), which permits unrestricted use, distribution, and reproduction in any medium, provided you give appropriate credit to the original author(s) and the source, provide a link to the Creative Commons license, and indicate if changes were made.

\section{References}

1. First Solar pushes verified CdTe cell efficiency to record $21.5 \%$, Press Release on 5 Feb 2015. http://www.pv-tech.org/news/first_ solar_pushes_verified_cdte_cell_efficiency_to_record_21.5

2. T.M. Razykov, C.S. Ferekides, D. Morel, E. Stefanakos, H.S. Ullal, H.M. Upadhyaya, Solar photovoltaic electricity: current status and future prospects. Sol. Energy 85, 1580-1608 (2011)

3. I.M. Dharmadasa, Review of the $\mathrm{CdCl}_{2}$ treatment used in CdS/ CdTe thin film solar cell development and new evidence towards improved understanding. Coatings 4(2), 282-307 (2014). doi:10. 3390/coatings 4020282

4. I.M. Dharmadasa, O.K. Echendu, F. Fauzi, H.I. Salim, N.A. AbdulManaf, J.B. Jasinski, A. Sherehiy, G. Sumanasekera, Study of Fermi level movement during $\mathrm{CdCl}_{2}$ treatment of $\mathrm{CdTe}$ thin films using ultra-violet photoemission spectroscopy. J. Mater. Mater. Electron. (2016). doi:10.1007/s10854-016-4391-y

5. I.M. Dharmadasa, O.K. Echendu, F. Fauzi, N.A. Abdul-Manaf, H.I. Salim, T. Druffel, R. Dharmadasa, B. Lavery, Effects of $\mathrm{CdCl}_{2}$ treatment on deep levels in CdTe and their implications on thin film solar cells: A comprehensive photoluminescence study. J. Mater. Sci.: Mater. Electron. 26(7), 4571-4583 (2015). doi:10. 1007/s10854-015-3090-4

6. B.M. Basol, Processing high efficiency CdTe solar cells. Int. J. Solar Energy 12, 25-35 (1992)

7. C. Ricárdez-Jiménez, G. Pérez-Hernández, J. Pantoja-Enriquez, B. Escobar-Morales, Q. Angulo-Córdova, L.L. Dias-Flores, M.E. Hernández-Torres, J.M. Gracia-Jiménez, N.R. Silva-González, X. Mathew, Effect of the post-deposition annealing with $\mathrm{CdCl}_{2}$ on the optical, structural and morphological properties of CdTe-films grown by CSS. IOP Conf. Ser. Mater. Sci. Eng. 45, 012014 (2013). doi:10.1088/1757-899X/45/1/012014

8. I.M. Dharmadasa, P.A. Bingham, O.K. Echendu, H.I. Salim, T. Druffel, R. Dharmadasa, G.U. Sumanasekera, R.R. Dharmasena, M.B. Dergacheva, K.A. Mit, K.A. Urazov, L. Bowen, M. Walls, A. Abbas, Fabrication of CdS/CdTe-based thin film solar cells using an electro-chemical technique. Coatings 4, 380-415 (2014). doi:10.3390/coatings4030380

9. O.K. Echendu, F. Fauzi, A.R. Weerasinghe, I.M. Dharmadasa, High short-circuit current density CdTe solar cells using allelectrodeposited semiconductors. Thin Solid Films 556, 529-534 (2014). doi:10.1016/j.tsf.2014.01.071

10. H.I. Salim, V. Patel, A. Abbas, M. Walls, I.M. Dharmadasa, Electrodeposition of CdTe thin films solar cells using nitrate precursor. J. Mater. Sci.: Mater. Electron. 26(5), 3119-3128 (2015). doi:10.1007/s10854-015-2805-x

11. N.A. Abdul-Manaf, H.I. Salim, M.L. Madugu, O.I. Olusola, I.M. Dharmadasa, Electro-plating and characterisation of CdTe thin films using $\mathrm{CdCl}_{2}$ as the cadmium source. Energies $8(10)$, 10883-10903 (2015)

12. K. Zanio, in Semiconductors and Semimetals, vol. 13, ed. by R.K. Willardson, A.C. Beer. Cadmium telluride (Academic Press, Cambridge, 1978)

13. M.P.R. Panicker, M. Knaster, F.A. Kroger, Cathodic deposition of CdTe from aqueous electrolytes. J. Electrochem. Soc.: Electrochem. Sci. Technol. 125(4), 566-572 (1978)

14. D. Lincot, Electrodeposition of semiconductors. Thin Solid Films 487, 40-48 (2005)

15. R.K. Pandey, S.N. Sahu, S. Chandra, Handbook of semiconductor electrodeposition, 1st edn. (Marcel Dekker Inc., New York, 1996)

16. D.G. Diso, F. Fauzi, O.K. Echendu and I.M. Dharmadasa, Optimisation of CdTe electrodeposition voltage for development of CdS/CdTe solar cells, in Proceeding of Solar Asia 2015, University of Pune, Pune, 2015

17. W. Jaegermann, A. Klein, T. Mayer, Interface engineering of inorganic thin-film solar cells. Mater--Sci. Chall. Adv. Phys. Concepts Adv. Mater. 21(42), 4196-4206 (2009). doi:10.1002/ adma. 200802457

18. Z. Sobiesierski, I.M. Dharmadasa, R.H. Williams, Correlation of photoluminescence measurements with the composition and electronic properties of chemically etched CdTe surfaces. Appl. Phys. Lett. 53(26), 2623-2625 (1988)

19. I.M. Dharmadasa, J.M. Thornton, R.H. Williams, Effects of surface treatments on Schottky barrier formation at metal/n-CdTe contacts. Appl. Phys. Lett. 54(2), 137 (1989)

20. I.M. Dharmadasa, Recent developments and progress on electrical contacts to $\mathrm{CdTe}, \mathrm{CdS}$ and $\mathrm{ZnSe}$ with special reference to barrier contacts to CdTe. Invited review paper. Prog. Cryst. Growth Charact. 36(4), 249-290 (1998)

21. I.M. Dharmadasa, Advances in thin film solar cells, a single authored book (Pan Stanford Publishing Ltd., Singapore, 2013) 
22. S.H. Shin, J. Bajaj, L.A. Moudy, D.T. Cheung, Characterisation of Te precipitates in CdTe crystals. Appl. Phys. Lett. 43, 68-70 (1983)

23. P.M. Amirtharaj, F.H. Pollak, Raman scattering study of the properties and removal of excess Te on CdTe surfaces. Appl. Phys. Lett. 45, 789-791 (1984)

24. H.N. Jayatirtha, D.O. Henderson, A. Burger, M.P. Volz, Study of tellurium precipitates in CdTe crystals. Appl. Phys. Lett. 62, 573-575 (1993)

25. M. Bugár, E. Belas, R. Grill, J. Procházka, S. Uxa, P. Hlidek, J. Franc, R. Fesh, P. Höschl, Inclusions elimination and resistivity restoration of CdTe: $\mathrm{Cl}$ crystals by two-step annealing. IEEE Trans. Nucl. Sci. 58, 1942-1948 (2011)

26. M. Ayoub, M. Hage-Ali, J.M. Koebel, A. Zumbiehl, F. Klotz, C. Rit, R. Regal, P. Fougères, P. Siffert, Annealing effects on defect levels of CdTe: $\mathrm{Cl}$ materials and the uniformity of the electrical properties. IEEE Trans. Nucl. Sci. 50, 229-237 (2003)

27. P. Fernández, Defect structure and luminescence properties of CdTe based compounds. J. Optoelectron. Adv. Mater. 5, 369-388 (2003) 